\title{
Ethnography of the slaughterhouse: A case of Nanyuki slaughterhouse in Laikipia County, Rift Valley, Kenya
}

\author{
Edwin Ambani Ameso ${ }^{1 *}$, Salome Atieno Bukachi ${ }^{1}$, Charles Owuor Olungah ${ }^{1}$ and Tobias Haller ${ }^{2}$
}

\begin{abstract}
This paper focuses on establishing actors and their roles in the slaughterhouse processes in the Nanyuki slaughterhouse of Laikipia County. This is understood through the lens of the food system approach, based on the study findings of an anthropological study of pastoralism in Laikipia County, Kenya. This paper is guided by the specific objectives aimed at establishing the actors and their roles and describing the effects that institutional settings and changes have on slaughterhouse operations. Using a new institutionalism approach in social anthropology, the paper focuses not only on the actors and their roles but also on how externally shaped beef prices and standards shape the rules regulating access to the food processing processes for pastoral actors. We argue that this has an impact on pastoral economies and the question if and how pastoralists are able to benefit from this change in the food system. The study also identifies institutional settings and changes related to management, security and health concerns that impact the slaughterhouse operations and processes resulting from the dispensation of the devolved system of governance in the country. Data collection was through key informant interviews and unstructured observation of the slaughterhouse. The findings reveal economic and social relationships among actors involved in slaughterhouse operations and processes. The study also identified changes in formal institutional settings that impact the slaughterhouse operations, notably movement and no-objection permits as well as transportation and condemnation certifications. As a result, increased scholarship is recommended into slaughterhouse operations and processes as a means to understand the value addition that pastoralism has on the economic and food sustainability of the pastoral regions, counties and the nation as a whole.
\end{abstract}

Keywords: Slaughterhouse operations, Institutional changes, Certifications, Meat condemnation, Food sustainability

\section{Introduction}

According to Fitzgerald (2010), the slaughterhouse is an institution where economic and geographic changes in the production of food, cultural attitudes towards killings, social changes in small communities and the changing sensibilities and relations between humans and livestock can be viewed. Juma (2015) similarly defines the slaughterhouse as a plant responsible for the slaughter of animals, and there are two types: the simple slaughterhouse that does very limited processing and the complex slaughterhouse that conducts extensive processing. Singh et al. (2014) regard a slaughterhouse as a facility where animals are butchered or killed for

\footnotetext{
*Correspondence: edwin_ameso@yahoo.com

${ }^{1}$ Institute of Anthropology, Gender and African Studies, University of Nairobi, P.O. BOX 30197, Nairobi 00100, Kenya

Full list of author information is available at the end of the article
}

consumption as food products. In addition, Cook et al. (2017) view a slaughterhouse as a place where animals are slaughtered for food, mainly meat. GOK (2012) defines meat as any portion which is intended for human consumption, whether fresh, chilled or frozen or otherwise processed by any means whatsoever.

In most developing countries like Kenya, slaughterhouses that represent excellent production sites for beef are in most cases slaughter slabs which are less mechanized and with limited reliance on technology (Afnabi et al. 2014: 477). An example of such is the Nanyuki slaughterhouse that is owned and operated by the county government of Laikipia. Lokuruka (2016) in his work on the slaughter practices in Kenya illustrates that over $70 \%$ of the country's livestock population is found in the arid and semi-arid lands (ASALs), most being reared by pastoralists such as the Maasai of Laikipia 
County. Thus, it is important to establish the actors and their roles in the slaughterhouses.

Troeger (2004) acknowledges that the slaughterhouse processes always involve some critical steps that need to be upheld in cutting of beef carcasses. Thus, Pleiter (2010) reckons that slaughtering is more of a meticulous process which involves factoring in the welfare of the livestock brought for slaughter through the use of humane slaughter methods tolerable by religion and legally acceptable by the Association for the Welfare of Animals Sydney, Australia. In addition, Pozzi et al. (2015) acknowledge that slaughtering to some degree should exhibit limited cruelty and be compassionate to animals to ensure that the livestock being slaughtered is fit for human consumption. This resulted in eliciting the institutional settings and changes in the slaughterhouse operations and processes.

\section{Study site}

This study was carried out in Laikipia County situated in the Rift Valley Region (Figure 1). The County borders Samburu County to the north, Isiolo County to the north-east, Meru County to the east, Nyeri County to the south-east, Nyandarua and Nakuru Counties to the south-west and Baringo County to the west (GOK 2013). The County covers an area of $9,462 \mathrm{~km}^{2}$ and has five administrative sub-counties, namely, Laikipia East, Laikipia North, Laikipia Central, Laikipia West, and Nyahururu (GOK 2014) (Figure 2).

Laikipia County consists mainly of a rangeland plateau with a varying altitude of 1,500 to 2,611 m above sea level at Ewaso Nyiro basin in the north and Marmanet forest. The County's climatic conditions are affected by a plateau bordered by the Great Rift Valley to the west, the Nyandarua Mountains to the south and Mount

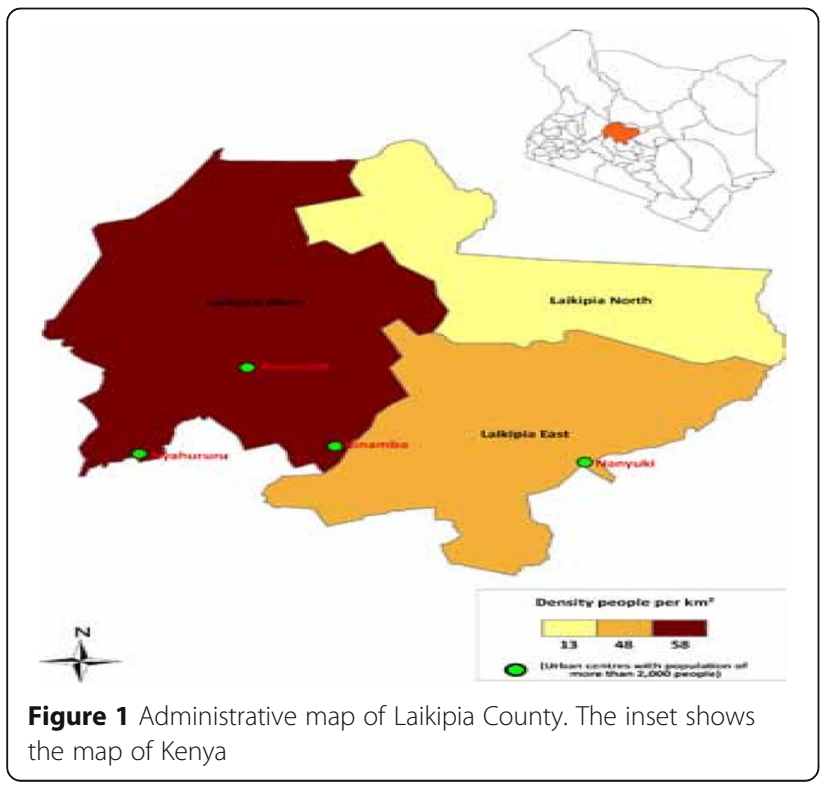

Kenya massifs to the south-east (GOK 2013). Large-scale agricultural activities all through the year cannot be fully supported by the county's scarce and unreliable rainfall patterns, notably in Laikipia north and Laikipia east subcounties. These sub-counties are largely pastoral zones with livestock production being a major economic activity.

\section{Methods}

\section{Study population and sampling procedure}

The study population consisted of Maasai pastoralists who were directly involved in slaughterhouse operations, veterinary officers, livestock buyers, livestock brokers, flayers and butchers who purchased either the live animals from the pastoralists at the slaughterhouse or the processed livestock products. The unit of analysis was the individual actor.

I interviewed 20 people out of which we had 16 men who included: pastoralists, butchers, livestock buyers, veterinary officers, green offal cleaners, splitters, skinners, and those who slaughter the livestock at the slaughterhouse. I also managed to interview 4 women at the slaughterhouse among them were 2 veterinary officers, a single pastoralist woman and one butcher. The proportion of women was less because of their low rate of engagement in slaughterhouse operations as compared to that of men. This study collected qualitative data only and relied on convenient sampling in selecting informants. Literature on the actors and their roles, and the institutional settings and changes at the slaughterhouse was reviewed. Interviews using key informant interview guides were conducted with pastoralists, livestock buyers, butchers, veterinary officers and flayers as key stakeholders at the slaughterhouse. This elicited information on the specific objectives, establishing actors and their roles in pastoralism at the slaughterhouse and describing the institutional settings and changes in pastoralism. Another data collecting method used at the slaughterhouse was unstructured observations, to give insights into the design and the terrain of the slaughterhouse and the level of physical interactions eliciting economic and social relationships among actors and their roles.

\section{Data processing and analysis}

The qualitative data obtained was sorted and interpreted in relation to the research objectives, to provide general interpretations of the findings, showing how thematic areas and issues interrelated.

\section{Findings and discussion}

\section{Livestock slaughtering in slaughterhouses}

In Kenya, the livestock industry not only contributes to the gross domestic product (GDP) and food sustainability but also supports the arid and semi-arid lands (ASALs) accounting for $90 \%$ of employment and close to $95 \%$ of household incomes (Nyariki et al. 2005). The Animal 


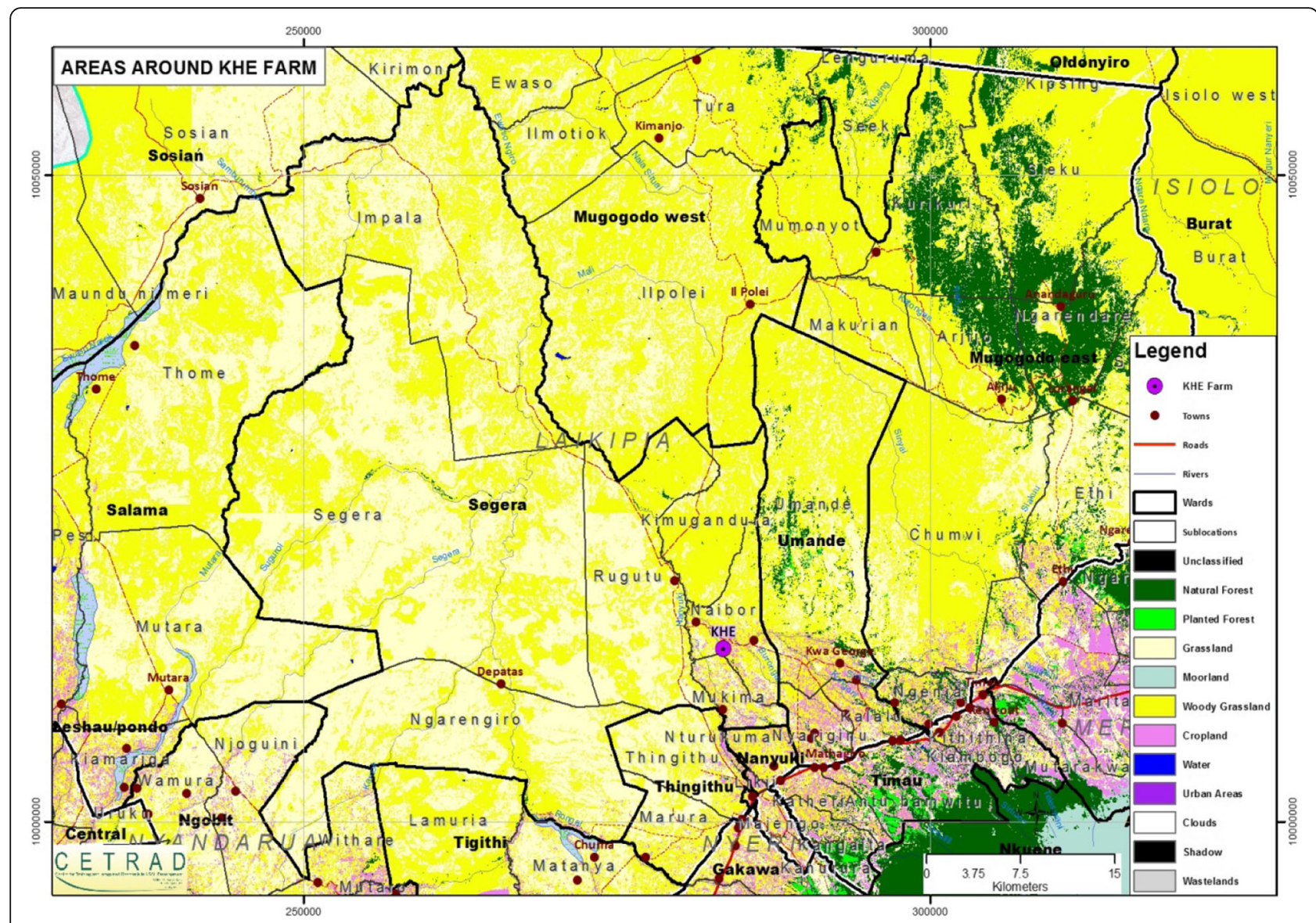

Figure 2 Map of the study area: Laikipia North sub-county

Welfare Association guidelines regulate the slaughter of livestock, and across the globe, countries have customized the guidelines to prevent animal cruelty; Kenya is no exception. The Kenya Society for the Prevention of Cruelty to Animals guides the humane slaughter of animals meant for human consumption (Lokuruka 2016). Slaughtering in Kenya is done in abattoirs based mostly in urban settings like Nanyuki. According to the revised Meat Act of 2012, a slaughterhouse reflects any place kept for the purpose of the slaughter of animals for human consumption (GOK 2012). In the slaughterhouse, a number of actors carry out varied tasks in the slaughter operations and processes which are greatly influenced by the formal institutional settings and changes.

\section{Actors and their roles in the slaughterhouse operations and processes}

The slaughterhouse is a quarantine area where three sets of butchers bring healthy livestock, livestock having difficulty in calving, livestock having injuries and livestock infested with livestock diseases to be slaughtered. Their motivation is purely profit-making through the sale of livestock products and by-products to a wide range of consumers. Livestock buyers are the first set of butchers, who frequent pastoral regions and purchase large consignments of live animals from pastoralists in livestock markets. They visit livestock markets such as Kimanjo, Rumuruti, Doldol and Naibor in Laikipia County among others, in the company of transporters. They represent business merchants whose sole drive is to profit from the sale of livestock products and by-products after processing at the slaughterhouse, selling to a wide customer base within and outside the county of Laikipia. The transporters are vehicle owners engaged in the ferrying of live animals to desired designations at a fee agreeable with the livestock buyers. In most cases, the desired designation for livestock buyers are slaughterhouses like Nanyuki slaughterhouse in Laikipia, Nyeri slaughterhouse in Nyeri and Huruma slaughterhouse in Nairobi Counties.

At the slaughterhouse, another set of butchers are found, who purchase either live animals or wait for the pastoralists to slaughter the livestock and purchase the livestock products and by-products based on weight. They are retailers and service providers with hotels and 
restaurants, who also have arrangements with other institutions for the supply of meat products. They are also driven by the need to maximize profit, be it at a cheaper cost. As a result, they interact with the pastoralists at the slaughterhouse only.

Livestock brokers are the third set of butchers, mainly pastoralists who frequent slaughterhouses to either process their livestock before selling or sell their live animals off to waiting butchers. They can be found inhabiting the pastoral regions and frequent the livestock markets to purchase livestock from fellow pastoralists, to nurture the animals and later resell at a profit. In a bid to maximize returns, they prefer to slaughter the livestock and sell off products and by-products separately. At the slaughterhouse the study established that pastoralists as primary producers in pastoralism could decide to sell of their live animals to butchers or they could also slaughter the livestock at their expense and incur the small cost of slaughtering and later selling of the livestock as dead weight. Dead weight is a term that is used to refer to the sell of meat after it has been declared fit for human consumption. At the slaughterhouse, the livestock products have a wide market, from individual customers holding ceremonies such as burials and weddings, retailers such as supermarkets and smallscale butchery operators purchasing beef at a relatively low cost based on the kilo scale for consumption, and also for resale to customers at a relatively higher price. For instance, a kilo of meat at the slaughterhouse costs 280 Kenyan Shillings, but at a butchery in an outlet like Chieni supermarket, a kilo of meat costs 400 Kenyan Shillings. Exchange rate of 100 Kenyan Shillings to USD 0.95 in 2016. Other customers are residents of Nairobi City County and other counties, hotels, security and training institutions like the Kenya Police Training College Kiganjo, National Youth Service Colleges in Gilgil and Naivasha and the army barracks in Isiolo and Laikipia counties.

However, slaughterhouse operations and processes also have other actors who ensure that health standards and requirements are met before livestock products are released for consumption. When the butchers bring livestock, their first interaction at the slaughterhouse is with the veterinary officer(s) at the offloading ramp. The veterinary officer conducts a clinical examination of the livestock by identifying the type, sex and breed as well as whether the livestock has difficulty in calving and screen for possible livestock diseases before they can be slaughtered at the ante-mortem examination phase. The livestock are screened for parasitic, bacterial, tick-borne and viral disease conditions like Echinococcus granulosus, Stilesia hepatica, liver flukes, East Coast fever, cowdriosis, babesiosis, anthrax and blackwater fever. After the screening by the veterinary officers, the butchers are allowed to move their livestock to the runway ready for slaughter, marking the end of a clinical examination.

A set of flayers take over the slaughterhouse operations from the veterinary officers in the ante-mortem examination. The first set of flayers is the slaughterhouse workers charged with slaughtering the livestock. They use a captive-bolt pistol to knock down the slaughter stock. This is considered to be a humane method of slaughter in line with the Islamic laws governing the consumption of Halal foods for members of the Islamic faith. The study was informed that the use of the Halal method ensures that the slaughterhouse workers pronounce the name of the Almighty God, Allah, before severing the neck of the slaughter stock, leaving it to bleed out to death and then detaching the head of the slaughter stock. Skinners are the second set of flayers, who open up the hide of the stock. The skinners also open up the carcass from the thorax to allow veterinary officers to inspect the organs and also remove the green and red offals.

The green offals are then taken by tripe cleaners into the tripe room for cleaning and washing before the veterinary officers can inspect them. The red offals, of lungs, heart and liver, are then washed by the skinners and made ready for the veterinary officers to inspect them in the post-mortem examination. Another set of flayers, (splitters), divide the remaining carcass into two and then wash the carcass to get rid of any traces of blood and bone before examination.

At the post-mortem examination area, the veterinary officers conduct visual examinations, palpation and incise the head, the tongue, the green and red offals and the rest of the carcass before declaring the products fit for human consumption. The examination inspects the slaughter stock for discoloration of the eyes, ears, nostrils, exposed muscles and tongue. In so doing, they screen for signs of jaundice, anemia, hemorrhages, abcesses and swellings. They also screen for liver cirrhosis, degeneration of the liver, inflammation of the capsule of the liver and any signs of parasitic cysts like liver flukes, Stilesia hepatica, abcesses and swelling of the liver. Additionally, they also look for possible conditions like pneumonia, pleurisy, parasitic cysts, Echinococcus granulosus, hemorrhages, Cysticercus bovis, and pericarditis.

After the post-mortem examination, the veterinary officers pass a judgement on the slaughter stock on whether it is fit for human consumption or not. The judgement stage is marked by the use of an edible red marker ink on the carcass that is passed fit for human consumption being roller stamped. The veterinary officers can pass their judgement on whether meat is fit for human consumption in two ways: either passing the meat unconditionally or passing the meat conditionally. 
The meat is passed unconditionally, when the inspectors have examined the carcass and passed it fit for human consumption without any conditions attached. They can also pass the meat conditionally when examination reveals the presence of parasitic cysts like Cysticercus bovis. The conditions are that when 1 to 5 cysts of the parasites are found, the meat is passed on condition that it is treated first either through sterilization (treating by steaming, boiling in a closed vault for about two and half hours at $77^{\circ} \mathrm{C}$ or rendering especially for pork) by heat or a cold treatment (freezing for 10 days at -10 degrees centigrade) of the meat before consumption and the infested parts are removed from the meat as well.

The study also found that conditional passing occurs when 6 to 20 parasitic cysts are found and treatment by either sterilization by heat or cold treatment is used. However, in this scenario, the inspectors release the meat to specific customers mainly colleges, childrens' homes, hospitals or other service, training and learning institutions as contact meat but cannot be sold as retail meat to consumers. However, the veterinary officers after inspecting the meat may during the judgment stage declared the meat unfit for human consumption and thus the head, the tongue, carcass, red and green offals are condemned. Condemnation of meat is based on either the health concerns that may occur if the meat finds its way to consumers or the discomfort with which consumers of meat may have with eating meat infested with liver flukes or Stilesia hepatica and other parasitic cysts. As aesthetics is one factor driving the consumption of meat, meat infested with parasitic cysts becomes less appealing, and thus, condemnation is necessitated.

On the one hand, condemnation can entail declaring certain parts of the slaughter stock infested with parasites unfit for human consumption and passing the rest of the carcass as fit. The study found that local condemnation occurs when liver flukes, abcesses, Stilesia hepatica and other parasitic cysts have been found on specific organs of the slaughter stock such as the head, liver and tongue. On the other hand, the slaughter stock in its totality may be declared unfit for human consumption and the use of its by-products leading to total condemnation. The study results revealed that the possible conditions that can result in total condemnation is when systemic infections or more than 20 cysts of Cysticercus bovis are found. When the slaughter stocks are condemned, they are disposed of by the use of the pit, burial, burning and use of a digester to dispose of selected condemned organs and by incineration of the slaughter stock when fully condemned.

\section{Institutional changes at the slaughterhouse}

With the creation of the county governments in Kenya, ownership of the government-owned slaughterhouses has changed from the municipal council to county governments that are managed under the devolved Ministry of Agriculture, Livestock and Fisheries at the county level. As a result, changes in the employment status of the slaughterhouse operators have been witnessed. The flayers, who were all once employees of the municipal council, were not fully absorbed as employees of the county government. As a result, the tripe cleaners are private sector employees who work on their own terms while the other sets of flayers are public employees of the county government working under different terms and conditions.

Changes in the roles and responsibilities of slaughterhouse operators have also been witnessed with the dispensation of the county governments. The veterinary officers who were once state employees and charged with dispensing supervisory roles in the slaughterhouses, namely, meat inspection and hygiene, are currently tasked with additional multiple roles. The veterinary officers have been placed in charge of the slaughterhouses and currently take up managerial and administrative roles.

For slaughter stocks to be transported to designated consumer market points, the meat inspectors ensure that the right vehicles that meet the new rules and regulations in accordance with the Meat Act are used. The transportation of meat is supposed to be by vehicle containing an enclosed vault and should be done between dawn and dusk. For meat to be transported, the veterinary officer inspecting the meat at the slaughterhouse needs to issue a certificate of meat transportation, detailing the origin of the meat and its end designation either within or outside the county to specified butcheries, hotels, supermarkets and institutions. Further conditions in the transportation of meat need to be met. For instance, the study found that for meat being transported to far-off destinations, defined in relation to kilometers and hours, require the meat carrier to be enclosed and contain a cold storage facility. For meat being transported on short distances, the use of a three-wheeler motorcycle, tuk tuk, a two-wheeler motorbike or a bicycle fitted with an enclosed meat container is allowed.

The movement of livestock from pastoral regions to the slaughterhouse is strictly regulated by new permit regulations that are meant to curb theft of livestock. When livestock is brought to the slaughterhouse, the veterinary officer requires the pastoralist or livestock buyer to present a no-objection permit. The noobjection permit is obtainable from the veterinary office in the county of livestock origin, and is a guarantee that the livestock have met the health requirements in relation to notifiable livestock diseases such as foot-andmouth disease and anthrax. A movement permit is also another that veterinary officers receive at the offloading ramp at the slaughterhouse, to countercheck whether 
the number of livestock transported corresponds with the number of livestock documented on the movement permits.

\section{Acknowledgements}

My deepest appreciation and gratitude is extended to the Twala womens' group for their accommodation during my data collection period, to the Rana family especially Peter Rana, Thomas Rana and Joseph Rana who tirelessly assisted me in the data collection and all my informants and discussants who participated in providing the information.

\section{Funding}

Not Applicable.

\section{Authors' contributions}

EAA, a Masters' student from the University of Nairobi, identified the research site, recruited the informants, collected and analyzed data. SB was my first supervisor from the initial conceptualization of the study topic to data collection and editing and reviewing of the manuscript. COO was my second supervisor from the proposal-writing stage to data collection and editing and reviewing of the manuscript. Moreover, as the director of the Institute of Anthropology, Gender and African studies, he also provided administrative support. All authors read and approved the final manuscript.

\section{Authors' information}

Edwin Ambani Ameso is a Masters' student from the Institute of Anthropology, Gender and African studies, University of Nairobi.

Salome Bukachi and Charles Owuor Olungah are senior research fellows in Anthropology. They work as senior lecturers at the University of Nairobi at the Institute of Anthropology, Gender and African Studies. They supervise many students at both Masters and PhD levels.

Tobias Haller is a professor of Anthropology at the Universitat Bern in

Switzerland. He also read, edited and reviewed the manuscript.

\section{Competing interests}

The authors declare that they have no competing interests.

\section{Publisher's Note}

Springer Nature remains neutral with regard to jurisdictional claims in published maps and institutional affiliations.

\section{Author details}

'Institute of Anthropology, Gender and African Studies, University of Nairobi, P.O. BOX 30197, Nairobi 00100, Kenya. ${ }^{2}$ Institute of Social Anthropology,

Universitat Bern, Lerchenweg 36, 3000 Bern 9, Switzerland.

Received: 5 October 2017 Accepted: 5 November 2017

Published online: 19 December 2017

\section{References}

Afnabi, B.R., R.P. Nameni, S.S. Kamdem, V.N. Ngwa, and J.J.E. Ngang. 2014. Typology of the Cameroon traditional slaughterhouse based on hygiene practices. Advances in Animal and Veterinary Sciences 2 (8): 477-487.

Cook, J.A.E., A.W. De Glanville, L.F. Thomas, S. Kariuki, B.M.C. Bronsvoort, and E.M. Fevre. 2017. Working conditions and public health risk in slaughterhouses in western Kenya. BMC Public Health 17: 14. 10.1186/S/2889-016-3923-y Accessed 25 Jan 2017.

Fitzgerald, J.A. 2010. A social history of the slaughterhouse: From inception to contemporary implications. Society of Human Ecology 17 (1): 58-69.

GOK. 2012. Laws of Kenya: Meat control act. Vol. Chapter 356. Nairobi: Government Press.

GOK. 2013. Laikipia County: First county development integrated development plan, 2013-2018. Nairobi: Government Press.

GOK. 2014. County assembly of Laikipia: Strategic plan, 2013-2018. Vol. Draft 3. Nairobi: Government Press.

Juma, E.K. 2015. An assessment of the various methods of slaughterhouse waste management and disposal in Nairobi County: A published Bachelor's project. University of Nairobi: University Press.

Lokuruka, M. 2016. A preliminary survey of animal handling and cultural slaughter practices among Kenyan communities: Potential influence on meat quality. African Journal of Food, Agriculture, Nutrition and Development 16 (1): 10666-10681.
Nyariki, M.D., B.F. Makau, W.N. Ekaya, and J.M. Gathuma. 2005. Guidelines for emergency livestock off-take handbook. Nairobi: The House of Hedges.

Pleiter, H. 2010. Review of stunning and Halal slaughter. Sydney: Meat \& Livestock Australia.

Pozzi, P.S., W. Geraisy, S. Barakeh, and M. Azaran. 2015. Principles of Jewish and Islamic slaughter with respect to OIE (World Organization for Animal Health) recommendations. Israel Journal of Veterinary Medicine 70 (3): 3-16.

Singh, L.A., S. Jamal, S.A. Baba, and M. Islam. 2014. Environmental and health impacts from slaughterhouses located on the city outskirts: A case study. Journal of Environmental Protection 5: 566-575.

Troeger, K. 2004. Overview of current and alternative slaughter practices. Biotechnologie, Agronomie, Société et Environnement 8 (4): 275-281.

\section{Submit your manuscript to a SpringerOpen ${ }^{\circ}$ journal and benefit from:}

- Convenient online submission

- Rigorous peer review

- Open access: articles freely available online

- High visibility within the field

- Retaining the copyright to your article

Submit your next manuscript at $\gg$ springeropen.com 